\title{
Impactos da Pandemia COVID-19 na economia, na sociedade, no redesenho das cadeias logísticas e no florescimento dos serviços de entrega: o caso brasileiro
}

Q Uly Soares e Melo Pulga

Faculdade de Arquitetura e Urbanismo, Universidade de Brasília, Brasil. ORCID: https://orcid.org/oooo-0oo1-8619-4173

\section{Joaquim José Guilherme de Aragão}

Faculdade de Arquitetura e Urbanismo, Universidade de Brasília, Brasil. ORCID: https://orcid.org/00oo-0002-1463-0180

\section{Yaeko Yamashita}

Faculdade de Arquitetura e Urbanismo, Universidade de Brasília, Brasil. ORCID: https://orcid.org/oooo-0002-3402-695X

Recibido: 5 de abril de 2021. Aceptado: 23 de junio de 2021.

\begin{abstract}
Resumo
As restrições impostas pela pandemia de COVID-19 impactaram diretamente os setores econômicos. Com todas as medidas de contenção e controle da pandemia, o setor de logística foi forçado a se reorganizar para atender às demandas reforçadas por produtos de higiene e assepsia. A mudança no mercado consumidor deu origem a novos nichos de serviços e organização da indústria, e os aplicativos de entrega de smartphones ganharam uma fatia importante no setor. O presente artigo analisa os impactos da pandemia na sociedade brasileira, nas mudanças nas cadeias de distribuição no Brasil em decorrência das medidas emergenciais durante a pandemia de COVID-19 e o papel de serviços de delivery nessa nova situação. Após uma breve resenha da literatura internacional sobre os tópicos tratados, as alterações no comportamento dos consumidores com relação aos bens de maior necessidade, o crescimento das plataformas de comércio eletrônico e a proliferação de serviços de delivery no País são relatados.
\end{abstract}




\title{
The delivery role as employment creation: restructuration proposal for chain management allied to delivery apps in COVID-19 pandemic
}

\begin{abstract}
Restrictions imposed for COVID-19 pandemics have had a direct impact in economic sectors. With all restraints and pandemic control measures, the logistics industry has been forced to reorganize itself to attend to the reinforced demands for hygiene and asepsis products. This market shift of consumption has given rise to new service niches and industry organization, whereby delivery smartphone applications have gained an important share. This article analyzes the impacts of the pandemic on Brazilian society, on changes in distribution chains in Brazil because of emergency measures during the COVID-19 pandemic and the role of delivery services in this new situation. After a brief review of the international literature on the topics covered, changes in consumer behavior in relation to the most needed goods, the growth of e-commerce platforms and the proliferation of delivery services in the country are reported.
\end{abstract}

Keywords: Distribution Logistics. Logistics Chain. Delivery Services. Transport. Covid-19.

Palabras clave: Logística de distribución. Cadena Logística. Servicios de Delivery. Transporte. Covid-19.

\section{Introdução}

Um dos maiores desafios da humanidade vem sendo enfrentado, desde janeiro de 2020 com a crescente proliferação do novo Coronavírus. Esse desafio de lidar com a pandemia infecciosa que tomou conta do mundo não é a primeira e nem será a última. A alta prevalência da doença coloca o coronavírus como uma das maiores pandemias de todos os tempos. Outras grandes pandemias ocorreram na história, mesmo que com características diferentes no tocante aos aspectos biológicos, sociais, temporais e geográficos. Contudo, costumam essas apresentar alguns pontos semelhantes tanto na forma de propagação quando de contenção destas doenças. Sobretudo, um ponto de semelhança é o comportamento humano diante as enfermidades, o caos social e a disseminação de informações, por vezes propositalmente falsas (Sanar, 2020).

A pandemia de COVID-19 causou impactos na economia em escala global. Tanto os países desenvolvidos quanto os países emergentes e em desenvolvimento passam por fortíssimas recessões. Com o encolhimento do PIB de países emergentes, foi previsto cerca de 10 anos de encolhimento de ganhos, com consequente aumento da pobreza, exclusão social e desemprego no mundo todo, podendo voltar a taxas referentes ao ano de 2017. O FMI (2021) estima que a gestão dos países frente à pandemia e a vacinação em massa expanda o PIB em 2021, mas as perspectivas de crescimento estão 5,3\% mais baixas ao comparar com o período antes da pandemia.

Uma gestão coerente, ao invés, deveria preparar a população, as empresas e os gestores públicos para as ações que pelo menos reduzam o risco humano, material e ambiental. Uma vez que, dada a violência incalculável dos desastres, grandes danos sejam produzidos, as medidas definidas na fase de preparação precisam ser executadas com eficiência; para depois se enfrentar a difícil recuperação.

O combate à pandemia do Coronavírus (COVID-19) e o prolongamento do isolamento social vêm provocando um embate político cada vez mais feroz, e o Brasil não pode fugir desse padrão. As recomendações das autoridades de saúde e dos governos 
estaduais de manter a quarentena contrapõem-se à necessidade de não causar impactos à economia, pois esses acarretariam graves danos não apenas às empresas e aos investidores, mas também à força de trabalho e às finanças públicas.

Um aspecto central na gestão de pandemias e desastres, de uma forma geral, é focar sobretudo na satisfação de necessidades de bens essenciais e, consequentemente, formular políticas públicas de estruturação emergencial dos respectivos mercados. Essas precauções dizem respeito não apenas a pandemias, mas também a diversos desastres (inundações, terremotos, incêndios, conflitos, entre outros), que ocorrem cada vez mais nos últimos tempos. Uma política de âmbito internacional deveria levar a que cada país adote uma estratégia de apoio permanente a setores emergenciais não apenas como estratégia de gestão de desastres, mas também de fomento econômico interno, favorecendo sobretudo as economias regionais e locais.

Parte-se, nesse artigo, do princípio de que estudos objetivos devem orientar governos e sociedades a buscar soluções efetivas em situações de dificuldade, harmonizando medidas de emergência e de manutenção da vida econômica. O escopo escolhido do artigo centra-se nas cadeias logísticas de suprimento de bens essenciais. Nessas cadeias, restrições impostas para contenção da pandemia de COVID-19 tiveram impacto direto no setor de logística, levando ao desabastecimento de produtos essenciais, tendo em vista que se trata de um setor que é encarregado do fluxo desses produtos desde sua produção até a entrega final.

Os primeiros meses da pandemia de COVID-19 foram marcados pela interrupção abrupta do fluxo entre a prestação de serviços e consumidor, como forma de contenção da contaminação, criando a necessidade de uma nova organização e adaptabilidade de vários setores, principalmente nos essenciais. Muito embora tenham se mantido em funcionamento com portas abertas, a redução da ida do consumidor a locais como supermercados e farmácias foi perceptível, abrindo espaço para serviços de delivery atuarem no intermédio e dar continuidade à cadeia. Nesse contexto, empresas como Ifood, Uber Eats e Rappi se enquadraram na categoria de serviços essenciais por prestarem serviço de entrega de produtos essenciais à população.

O desenvolvimento dessas plataformas requer uma estruturação conectada não só via internet, mas também de informação para o mercado por meio de bancos de dados e informações em tempo real para uma adaptabilidade mais rápida, eficiente e segura. A adaptação da logística como atividade essencial é cada vez mais próxima de uma realidade virtual, em que a potencialidade de atuação de diversos agentes pode promover a reestruturação do mercado e até a geração de empregos. Por exemplo, torres de controle (TC), e a Logística de Cinco Partes (5PL) surgem nesse cenário como plataformas, que deveriam ser utilizadas pelo Estado para monitorar o abastecimento de bens essenciais aos cidadãos (Ivaschenko, 2014; Hofman, 2014; Rustenburg 2016 e Giusti et al., 2019). Assim, o Estado poderá oferecer suporte aos setores essenciais e à logística de distribuição e transporte e potencializa a geração de empregos na última milha com o agente delivery.

É objetivo do presente artigo, nesse contexto, de estudar, a título ainda exploratório, os vínculos entre a disrupção promovida pela pandemia em diversos planos da sociedade, as mudanças comportamentais no provimento dos bens necessários de consumo por parte das famílias, assim como o fortalecimento de plataformas e de serviços de delivery, tendo por caso de estudo a situação no Brasil. Metodologicamente, buscou-se listar para cada tema estudos bibliométricos, e complementá-los com publicações selecionadas que tangem aspectos importantes da relação entre a pandemia, os processos disruptivos, as inovações logísticas e o processo de entrega (delivery). 
O artigo estrutura-se, assim, da seguinte maneira: à essa introdução segue uma resenha literária sobre mudanças comportamentais dos consumidores, a emergência de plataformas comerciais e o avanço do transporte de delivery. Subsequentemente, explora-se o caso brasileiro no que tange os impactos sofridos no País; o avanço das plataformas de comércio eletrônico; e o impulsionamento dos serviços de delivery, contratados pelas plataformas, com suas consequências trabalhistas. $\mathrm{O}$ artigo finaliza com as conclusões.

\section{Resenha literária}

\section{Impactos gerais da Pandemia na economia e na sociedade}

A pandemia COVID 19, que afetou a vida da humanidade inteira, não poderia deixar de ser um tópico principal da pesquisa, desde o início de 2020 (Meyer et al.2021). Oliveira et al. (2021) conseguiram identificar mais de 2600 artigos, publicados em 860 revistas e envolvendo 9791 autores de 3365 instituições de pesquisa em 105 países. As principais origens dessa produção são a China, Estados Unidos, Reino Unido e Itália, ficando o Brasil na $15^{\mathrm{a}}$ posição. Como era de se esperar, são as revistas ligadas às ciências médicas que produziram o maior número de publicações.

A análise de Odunayu e Aim (2020) sobre os efeitos da pandemia inicia nos graves efeitos da paralização geral dos negócios, especialmente nos fluxos de viagem, que afetou mais de 200 países. Originalmente aplicada como meio de redução da transmissão, as medidas de distanciamento social produziram inicialmente uma falta de oferta de força de trabalho, especialmente no setor de logística. Por outro lado, demandas domésticas de alimentos provocaram ondas de compras preventivas, com características de pânico social. As falhas nas redes logísticas afetaram o funcionamento das mais diversas atividades econômicas, aumentando o risco de uma grave depressão em escala mundial.

Especialmente as cadeias dos bens essenciais de consumo foram afetadas. No que tange os produtos alimentícios, as disfunções tanto na logística de suprimento quanto na de distribuição podem afetar a produção agrícola, implicando na escassez e no encarecimento dos alimentos. Semelhante danos podem ser percebidos na produção industrial como um todo. De uma forma mais geral, as cadeias globais, que regem cada vez mais fortemente o atendimento das necessidades, sofreram graves disrupções, agravando mais ainda o suprimento, sem que políticas nacionais de segurança de abastecimento tivessem podido oferecer um alívio no tempo necessário.

Swanson e Santamaria (2021) conseguiram identificar 3 clusters de artigos com referência às cadeias de suprimento: um primeiro relacionado a fontes e demandas das cadeias de suprimento no sistema de saúde ( $46 \%$ das publicações levantadas); um segundo, relacionado com pesquisa e desenvolvimento de tecnologias de cadeias de suprimento (54\%); e um terceiro relacionado com a gestão estratégica e operacional das cadeias (53\% das publicações); sendo que diversos artigos abrangiam dois ou três dos clusters.

Os autores observam a preocupação das companhias e dos governos em preservar suas cadeias de suprimento e com a dependência do fornecimento internacional, sendo que a globalização das cadeias aumentou consideravelmente a vulnerabilidade. Entretanto, a busca de redução dessa dependência pode piorar o desemprego e a pobreza especialmente nos países que dependem da exportação de matérias-primas. Alternativamente, a rede de colaboração e a expansão das redes de conexão das cadeias poderiam se fortalecer, com apoio dos organismos que regulam o comércio internacional. Isso abriria um novo campo de pesquisa para modelagens que analisariam os efeitos das políticas governamentais no comércio internacional, campo esse ainda pouco explorado. De 
qualquer forma, os autores concluem que a pandemia encontrou os governos despreparados para lidar com a pandemia, e que medidas de prevenção contra desastres desse tipo deveriam constar das prioridades das políticas públicas.

Em seu estudo sobre os efeitos da pandemia na economia, Verma e Gustafsson (2020) concluem:

a) As restrições impostas para reduzir o nível de contágio impactaram severamente a atividade econômica em quase todo o setor, especialmente naqueles que presentam maior contato direto entre vendedores e provedores de serviço, de um lado, e os consumidores, de outro. Muitas empresas tiveram de enfrentar bancarrota, reduzindo a capacidade de produção e provocando desemprego. No plano das finanças públicas, houve um aumento substancial da dívida tanto da parte das empresas quanto do governo;

b) No entanto, as empresas que sobreviveram foram levadas a renovar seus modelos operacionais focando mais diretamente os consumidores e aumentando a agilidade frente às mudanças;

c) Ao mesmo tempo, a pandemia ameaçou a sobrevivência de startups, em função dos investidores reduzirem sua exposição em negócios inovadores e priorizarem a modernização de cadeias de suprimento de bens essenciais, inclusive de serviços médicos. Esse efeito foi também resultado da redução das possibilidades de encontros espontâneos, tão importantes para criar relações de confiança nesse setor;

d) De acordo com nível de otimismo ou pessimismo, o fluxo de comércio reduzirá por algum tempo de 13 a 32 porcento, até em função do fechamento de diversas fronteiras. Entretanto, alguns fluxos podem se beneficiar do uso mais intenso do homeworking;

e) A crise afetou 3,3 bilhões de empregados no mundo todo, especialmente em função da imposição do distanciamento social, voluntário ou imposto. Muitos empregados enfrentaram queda drástica dos rendimentos, especialmente nos setores de comida, restauração, vareje, indústria e atividades administrativas. Essa queda agrava adicionalmente diversos negócios;

f) No que tange a evolução da tecnologia de dados, houve um avanço no uso de GPS, big data e de dados em tempo real, o que facilita um conhecimento maior dos efeitos da crise e a elaboração de medidas de sua gestão, especialmente aquelas que lidam com decisões difíceis do ponto de vista social;

g) Esse mesmo avanço possibilitou a difusão da educação e do trabalho remotos. Igualmente, informações de interesse da saúde pública, como dados espaciais, facilitam a detecção dos focos de infecção e de sua difusão. Esses avanços são utilizados para aprofundar novas tecnologias relacionadas à Indústria 4.0 (IoT, AI, drones, veículos autônomos, telemedicina em blockchain, e gestão ambiental). Por outro lado, eles podem produzir uma proliferação incontrolável de dados de baixa qualidade ("infodemia").

Kim (2021) analisou os impactos da pandemia no setor de transporte, que foram, primeiramente, fortes nas viagens e nos movimentos interurbanos e interregionais, implicando em uma redução de 60 a $80 \%$ da capacidade dos principais operadores. No interior desse setor, o transporte aéreo foi o que terá sido o mais afetado, redundando em um desemprego de mais do que $13 \%$ da força de trabalho. Especialmente as empresas low cost foram duramente prejudicadas.

Outro subsetor duramente impactado foi o de cruzeiros marítimos. Ao mesmo tempo que a continuidade das operações foram afetadas pelo declínio das atividades econômicas, elas são alvo de severa vigilância por serem vetores de transmissão. Já o transporte local e regional de passageiros sofreu uma redução de $55 \%$ das viagens, eis que $80 \%$ da população limitaram suas atividades; nesse setor, houve redução de $68 \%$ das distâncias 
percorridas pelos viajantes; em contrapartida, a participação dos que viajam a trabalho aumentou consideravelmente, até por causa da introdução emergencial do ensino à distância. Deslocamentos até supermercados ficaram estáveis.

\section{Impactos da Pandemia nas Cadeias de Provimento de Bens Essenciais}

O estudo bibliométrico de Chowdury et al. (2021) aponta o esforço da literatura em analisar os impactos da pandemia, mas também as estratégias de resiliência. As cadeias de suprimento que mereceram maior atenção foram a de produtos médicos e de alimentos, onde os esforços ainda não conseguiram chegar a uma base conceitual mais robusta, baseando-se em estudos de caso, por vezes mais opinativos. No que tange às recomendações para melhorar a resiliência das cadeias, elas foram divididas em preparação, resposta e recuperação, onde diversas propostas foram alocadas a cada uma dessas etapas da gestão de desastres.

O levantamento bibliométrico de Farooq et al. (2021), por sua vez, indica um volume considerável de publicações centradas em estratégias, modelos, quadros de referência e recomendações voltadas para a redução de disrupções e a gestão de riscos provenientes de desastres, explorando os espaços abertos pela revolução digital. A literatura explorada transcende, porém, a pandemia COVID-19 e abrange também desastres e conflitos em geral. Com relação à pandemia em tela, boa parte da literatura foca na crise humanitária causada pela disrupção.

Nesse campo de indagações, a gestão de risco de cadeias de suprimento adquire um espaço importante, onde a transição digital é focada como um fenômeno crucial. Detectou-se a importância do desempenho das cadeias, ou a falta deste, no controle ou descontrole da disrupção. Os autores detectam como o início da pandemia e a retração brutal da demanda paralisaram diversas cadeias, mas, em uma segunda etapa, algumas conseguiram florescer, especialmente as relacionadas com negócios online, relevando a força das plataformas eletrônicas. Ao revés, os negócios dependentes de meios físicos foram os mais desafiados. Por isso, a modelagem de redes de suprimento aparece como um tópico promissor de pesquisa, assim como o reforço de cadeias nacionais internas.

Segundo Verma e Gustafsson (2020), a pandemia continua ainda a provocar disrupção de cadeias industriais e de suprimento, trazendo consequências graves para os consumidores, negócios, empresas e a economia global. Especialmente as cadeias de bens necessárias foram afetadas. Em contrapartida, as empresas estão modificando suas cadeias de suprimento e tecnologias de produção, com vistas a assegurar pelo menos a continuidade dos negócios. As medidas abrangem controles funcionais cruzados, coordenação em níveis regional e internacional, aumento de estoques de segurança, modelos de logística de carga, programas de atendimento dos clientes, inclusive fluxos de devolução.

Ao estudarem as cadeias de suprimento médico, Odunayo e Adim (2020) apontam as falhas na provisão de máscaras de qualidade (N-95) e desinfetantes das mãos, expondo sobretudo os profissionais da saúde ao risco de contágio. A escassez abrangeu também os aparelhos de ventilação, sobretudo na medida em que alguns governos conseguiram concentrar sua aquisição para seus próprios países.

Já no que tange a cadeia de alimentos, sua escassez é aprofundada pelo distanciamento social, até porque sua logística e distribuição apresentam uso mais intensivo de força de trabalho. Assim, a crise de saúde se transbordou para se tornar uma crise de alimentos. A centralização global de parte das cadeias agravou mais ainda o desabastecimento, revelando a estrutura delicada do suprimento. 
As principais mudanças operadas na pandemia abrangeram a melhoria da logística do varejo, onde a política de estoque focou mais a falta de provisão do que a otimização dos custos de estoques. Nesse campo, as inovações tecnológicas tiveram um papel crucial, abrindo espaços para pagamentos sem contrato, a garantia de espaçamento entre os clientes e o pessoal nas lojas e, mais importante do que outras, a revolução do comércio eletrônico. Essas transformações colocam desafio para o período após a pandemia, pois novos processos de abastecimento e distribuição passaram a ser elementos fundamentais das cadeias. Entre eles destacam-se sobretudo a robotização dos armazéns e a capacidade de resposta aos pedidos, tanto em termos de tempo quanto de exatidão das ordens de compra (Odunayo e Adim, op. cit.).

No campo dos modelos de simulação, a contribuição de Sinha et al. (2020) foca nas consequências da pandemia e da etapa pós-pandêmica no desenvolvimento técnico das cadeias de suprimento, que foram afetadas de uma forma sistêmica pelas disrupções, com graves impactos para o suprimento, os negócios, a renda e o consumo. As modelagens devem mapear os diversos fatores econômicos e operacionais, com vistas a prover ferramentas para as políticas de enfrentamento de desastres. Mesmo que certas demandas cresçam durante a pandemia, paralizações nas cadeias anulam seus efeitos econômicos positivos. A simulação deve abranger, igualmente, as relações comerciais entre os países e as técnicas de produção, que por vezes reforçam a precariedade sanitária.

\section{Emergência de Plataformas Virtuais}

O estudo da OCDE (OECD, 2020) aponta para uma rápida expansão do comércio eletrônico durante a pandemia. Essa evolução possibilitou precisamente, durante a crise, o acesso a uma enorme variedade de produtos e serviços, resgatando a operação de um número grande de empresas, a despeito das medidas de distanciamento social. Novas empresas e novos produtos e segmentos de consumidores deixaram de abranger apenas produtos de luxo, mas também abraçaram produtos de primeira necessidade. Por outro lado, a revolução do comércio eletrônico deixará profundas sequelas para a era após a pandemia, reforçando a resiliência contra crises similares, a mudança de hábitos de consumo e estratégias de investimento.

Entretanto, as inovações ainda não permitem uma distribuição social ampla dos benefícios, aprofundando fossos entre camadas da população e os países. Subsequentemente, a política econômica deverá assegurar a melhoria da conectividade entre as cadeias, a inclusão financeira, a segurança digital, o respeito à privacidade e a proteção dos direitos do consumidor. A política regulatória deverá, de um lado, reduzir as incertezas dos negócios interconectados, mas, por outro lado, promover sobretudo a inserção de pequenas e médias empresas (ibid.).

A investigação de Galhotra e Ayushi (2020) abordou o uso das plataformas ao longo de diversas fases da pandemia, onde foi verificado seu uso não apenas para abastecimento de bens essenciais, mas também para o lazer. $\mathrm{O}$ aprendizado de seu uso não apresentou grandes dificuldades, e ficaram, ao revés, maravilhados com a amigabilidade e a utilidade dos aplicativos. A transformação digital atingiu também o ensino, pela introdução de aulas à distância. Entretanto, atitudes de segurança foram reforçadas, especialmente na aquisição de bens essenciais.

Analisando a situação no Vietnã, Van Kien Pham et al. (2020) analisam a mudança de comportamento dos consumidores operada especialmente durante a pandemia. Observou-se uma reavaliação, por parte destes, das suas necessidades, mas também da utilidade das plataformas. A adesão a essas só foi contida por considerações de solidariedade aos vendedores de confiança. Mas, de uma forma geral, a pandemia não afetou profundamente as estratégias de marketing das empresas. 
Em um estudo de mercado focado na Amazon, MacDonald (2020) confirmou as mudanças previstas no uso das plataformas, especialmente das de maior abrangência global. O perfil de consumo que passa pelas encomendas varia de país a país, e de continente para continente. Enquanto em alguns, alimentos e bebidas assumem a prioridade, em outros, bens de entretenimento e de esportes predominam. Prevê-se que essas tendências afetem de forma diferenciada a estrutura de diversos segmentos de consumo.

\section{Serviços de Delivery}

O motivo central que conecta a cadeia de bens essenciais ao serviço de delivery é a possibilidade da continuidade da cadeia mesmo em situação de lockdown. Durante a pandemia, a crescente demanda de pedidos por aplicativo direcionou grande número de novos entregadores para as plataformas. Além disso, as empresas responsáveis pelos principais aplicativos procuraram realizar as entregas por meio de parcerias com outras empresas terceirizadas.

Os serviços de delivery que utilizam mecanismos de governança em rede têm desempenho significativamente mais alto, em comparação aqueles e àquelas que não os utilizam (Swierczek, 2019). Tais mecanismos podem auxiliar na ampliação da sustentabilidade social e ambiental, que, além dos ganhos diretos, contribuem também para a imagem organizacional das empresas (Gimenez e Sierra, 2013 e Rajindra et al., 2019).

Unnikrishnan e Figliozzi (2020) mostram que a pandemia acelerou os pedidos de delivery, sobretudo nos lares de maior poder aquisitivo, sobretudo em função do maior acesso a serviços de telecomunicação. Esse segmento foi o que mais beneficiou plataformas de produtos diversificados, como a Amazon, UPS e FedEx. Para o setor de alimentos e restaurantes, os pedidos de atendimento imediato são críticos. Esse mercado requer logística de última milha eficiente, mas pode apresentar uma estabilidade e recorrência de pedidos maior, em função do aumento do trabalho remoto. Em contrapartida, a demanda de bens de luxo decresceu. De qualquer forma, a disponibilidade de um serviço eficiente de delivery é indispensável para a sobrevivência.

Em um estudo focado na Índia, Mehrolia et al. (2021) confirma que os usuários que pedem comida nas plataformas de alimentação são os menos suscetíveis a riscos existenciais e consumem produtos de alta qualidade. As encomendas por meio das plataformas resultam de uma percepção maior de risco de contaminação. Ao mesmo tempo, essa percepção leva a uma seleção mais cuidadosa dos itens a comprar, não apenas no que tange a segurança dos produtos, mas também o que pretendem fazer com a renda não consumida, por exemplo, para guardar para viagens após a pandemia.

Esses resultados implicam, segundo os autores, que as operadoras de aplicativos não devem apenas focar no comportamento de prudência dos seus clientes, mas também entender os deslocamentos de suas preferências, em função das precauções. Uma aspiração de maior higiene, por exemplo, pode ser um indicativo para restaurantes. Um outro seria aperfeiçoar formas de pagamento sem contato, ou até de aumentar a higiene do processo de entrega das mercadorias.

Srinivas e Marathe (2021) relatam uma das inovações referentes à "logística de última milha" ocorridas durante a pandemia que são as "lojas móveis". Trata-se aqui de caminhões que carregam uma variedade de produtos de acordo com o perfil local e respectiva estimativa de demanda para diferentes itens. Esses provedores possuem uma capacidade de estoque mais adequada aos bens efetivamente procurados, e aceleram a respectiva provisão. Esse tipo de comércio é rapidamente adaptável a variações dos pedidos, podendo ter desempenho superior ao comércio eletrônico. 


\section{Impactos da pandemia na economia brasileira}

Conforme Silber (2020), os impactos da pandemia agravaram mais ainda os efeitos já crônicos do baixo dinamismo desde a década de 1980, agudizado ainda por uma recessão profunda em 2015-2016, quando o PIB teve uma queda cumulativa de 6,7\%. Conforme o autor:

Essas crises aumentaram significativamente a informalidade no mercado de trabalho, atingindo $48 \%$ da população em meados de 2020. Dada a resposta inadequada do governo brasileiro à questão sanitária, os efeitos da pandemia estão sendo devastadores. A previsão de queda do PIB per capita em 2020 é de 6,5\%, e no momento em que este artigo estava sendo escrito, 720 mil empresas já tinham desaparecido do país, 13 milhões de trabalhadores estavam desempregados, 5,7 milhões eram desalentados e 32 milhões estavam subempregados; ou seja, $52,8 \% \mathrm{da}$ população economicamente ativa estavam marginalizados do mercado de trabalho.

Dado que o Brasil tem a quinta pior distribuição de renda do mundo, além do problema econômico, o problema social criou uma pressão política por mudanças que contemplem a enorme iniquidade na sociedade brasileira, com um contingente imenso de população vulnerável pelas crises e exclusão social.

Conforme Bosquerolli et al. (2020), a pandemia causou em seu pior mês (março de 2020) uma queda nos setores de indústria, comércio e serviço. Nesse mês, a produção industrial recuou 9,1\% frente ao mês anterior, "e os bens de consumo duráveis e bens de capital foram os que apresentaram maiores retrações: $-23,5 \%$ e $-15,2 \%$, respectivamente".

Alguns produtos relacionados com o consumo de primeira necessidade (papel higiênico, absorventes, fraldas, desodorantes, sabões, detergentes, xampus, seringas, agulhas, luvas de borracha, artefatos de proteção e caixões) acusaram aumento da produção, sem, contudo, ter promovido um crescimento geral na economia (ibid.).

\section{Impactos Sociais}

Os abismos sociais latentes no Brasil se ampliaram ainda mais durante após a pandemia, e a situação já persistente de desigualdade coloca a população de baixa renda em situação ainda mais agravada de vulnerabilidade (Matta et al. 2021). A falta de acesso a insumos, bens essenciais e condições sanitárias são determinantes na mortalidade e na disseminação do vírus, e essa falta é acirrada pela precariedade do mercado de trabalho. O Índice de Condição de Trabalho (ICT) teve queda de 12\%, demonstrando a deterioração do mercado em função da crise (DIEESE, 2020). Outras estatísticas que retratam o estado de calamidade são: a) o aumento de 3,9\% da desocupação no país; b) $41 \%$ dos domicílios do território que solicitaram o auxílio emergencial; c) $19,6 \%$ de pessoas ocupadas sofreram queda de rendimento (IBGE PNAD Covid-19, 2020).

\section{Disrupções nas cadeias de suprimento}

Disrupções nas cadeias de suprimento resultaram em baixa oferta e disponibilidade de produtos essenciais para o consumo e para o abastecimento de hospitais e clínicas. Observou-se falta em produtos tais como álcool em gel, álcool líquido, medicamentos e EPIs em vários estados do Brasil, levando ao seu racionamento em hospitais públicos e particulares com mais de cinco mil denúncias registradas pelo Conselho Federal de Enfermagem acusando falta ou restrição de EPI (Góes et. al., 2020). A queda em produções de bens essenciais criou instabilidade na cadeia como um todo, que, quando somada à alta do dólar, produziu um encarecimento dos produtos ao para o consumidor final (Costa et al., 2020). 
O abastecimento de insumos importados para abastecimento de indústrias sofreu interrupção, impactando na logística de vários setores que dependem de produtos do setor primário e secundário, principalmente em países em desenvolvimento. O escoamento reduzido de produtos causou o fechamento de empresas e indústrias que dependiam de seu abastecimento. Apesar do maior custo imediato, a aquisição de matérias-primas com produtores locais e a subsequente redução de inventários em armazéns auxiliou na minimização dos impactos causados pela pandemia (Fernandes, 2020).

O tempo acrescido de resposta às demandas reflete também um processo mais amplo de desindustrialização, da dependência de importações e do atraso tecnológico em relação a outros países. Portanto, faz-se necessária a reestruturação dos mercados nacionais através de políticas e estratégias nacionais de desenvolvimento voltadas para a industrialização, o investimento em pesquisas e a ampliação de sistemas públicos como o SUS para gerenciar a crises sanitárias como a COVID-19 (Sabbatini e Fonseca, 2021).

\section{Impacto no Setor Logístico}

O encolhimento de $58 \%$ do setor de logística e transporte reflete o impacto que houve nos pequenos negócios. As 243.462 empresas do setor registraram variação em taxas de emprego de -10,7\% se comparados com dados do primeiro e segundo trimestre de 2020 (IBGE, 2021). Mas em contraponto às quedas, setores que conseguiram reestruturar suas vendas e adequar ao mercado online e delivery obtiveram melhor desempenho em meio à crise. Esse movimento abriu espaço não só para o setor de comércio virtual, mas também para o delivery e para a armazenagem em centros de distribuição (Costa et al. 2020). Empresas que faziam o uso de plataformas digitais passaram de $37 \%$ para $44 \%$ em 2020. Consequentemente, as atividades correlatas ao comércio eletrônico também demonstraram tendencia de crescimento. Também pôde ser observado aumento do número de vendas de motocicletas, influenciado pela atuação e expansão do delivery no Brasil (SEBRAE, 2020).

\section{Cadeia logística de serviços essenciais durante a pandemia}

\section{A cadeia de bens essenciais}

O Decreto ${ }^{\circ}$ 10.329/2020 específica serviços que não podem interromper suas atividades por se tratar de serviços essenciais. Entre eles estão os serviços logísticos e de transporte e serviços de abastecimento. Nesse contexto, empresas como Ifood, Uber Eats e Rappi se enquadraram nas categorias de atividades essenciais por prestarem serviço de entrega de produtos essenciais à população (Aquino et al., 2020).

Extrai-se aqui o art. $3^{\circ}$ do diploma legal referido:

Art. $3^{\circ}$ As medidas previstas na Lei $n^{\circ}$ 13.979, de 2020 deverão resguardar o exercício e o funcionamento dos serviços públicos e atividades essenciais a que se refere o $\S 1^{\circ}$.

XXII - serviços de transporte, armazenamento, entrega e logística de cargas em geral;

XLIV - atividades de comércio de bens e serviços, incluídas aquelas de alimentação, repouso, limpeza, higiene, comercialização, manutenção e assistência técnica 
automotivas, de conveniência e congêneres, destinadas a assegurar o transporte e as atividades logísticas de todos os tipos de carga e de pessoas em rodovias e estradas.

Durante o surto de COVID-19, o fluxo de suprimento entre atacadista e varejista para o consumidor foi interrompido pela restrição ao de deslocamento e à aglomeração, impondo uma nova organização do transporte e do fluxo de informação. $\mathrm{O}$ agente delivery, intermediário entre esses dois agentes e o consumidor final (ver Figura 1), ganhou mais espaço com a nova situação deste último e passou a ter papel importante na continuidade da cadeia como serviço essencial (Abilio et al., 2020).

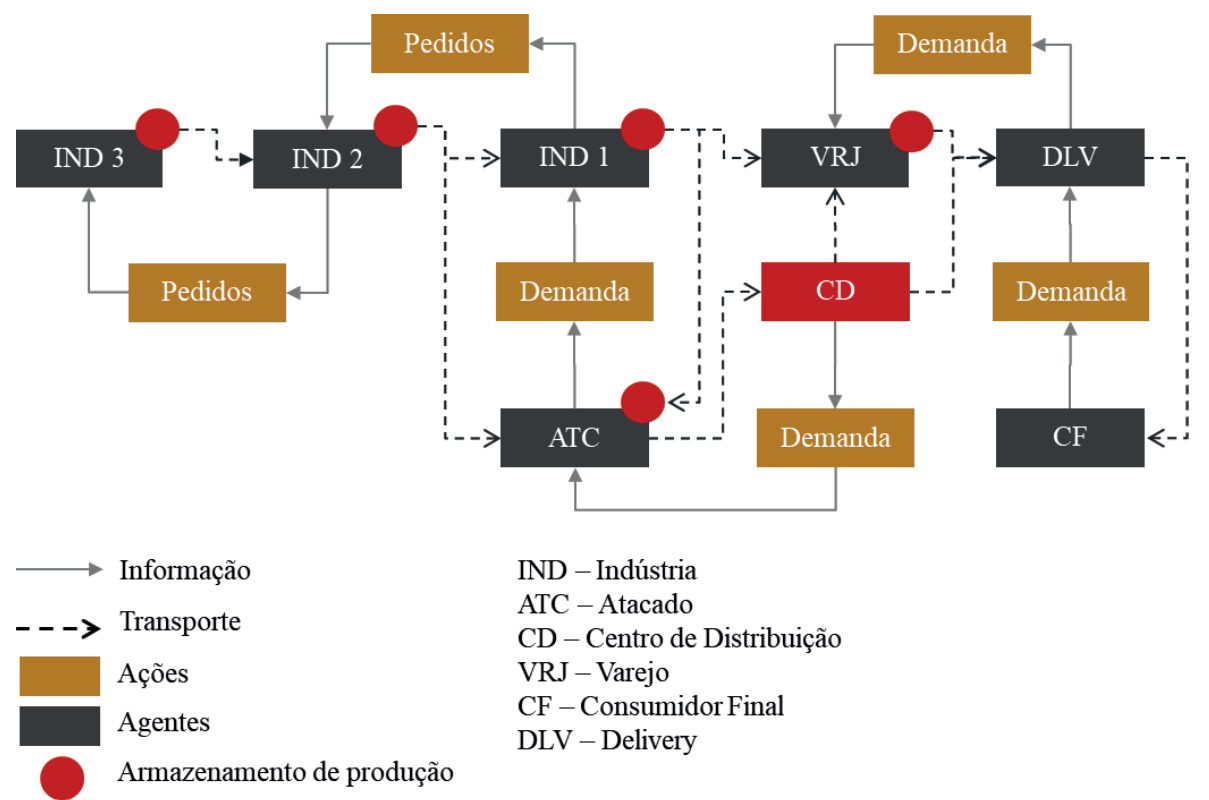

Figura 1. Cadeia logística com atuação do agente de delivery. Fonte: elaborado pelos autores.

O serviço prestado por entregadores por meio de aplicativos em dispositivos móveis vem cumprindo funções de entrega de alimentos preparados, produtos farmacêuticos, e produtos já presentes no comércio eletrônico que englobam os bens de consumo, alimentação e EPIs (Firjan, 2020). A logística entra como o estruturador central desses fluxos, mas de maneira conectada e rápida, construída como uma rede de prestação de serviços do início ao fim da cadeia, com a entrega ao consumidor cliente final (Lassere, 2004).

\section{Novo comportamento de compras e o papel do comércio eletrônico no Brasil}

Segundo pesquisa realizada pelo SEBRAE (2020), entrevistados responderam que a preparação de alimentos em casa confere a maior sensação de segurança, seguida de alimentos semiprontos com finalização em casa; e em terceiro lugar, os alimentos entregues por delivery. A pesquisa também indica que a seleção do serviço de delivery se dá pela preocupação com o modo de preparo dos alimentos; e a higiene tem o maior peso na escolha pelos consumidores dos por restaurantes fornecedores. No quesito confiabilidade, os entrevistados demonstraram tendência positiva de confiança em aplicativos de delivery. Vendas digitais de produtos de saúde e higiene e sua entrega por delivery cresceram $111 \%$, e supermercados $80 \%$, quando provenientes de supermercados.

O portal Mercado Livre, no primeiro trimestre de 2020, registrou aumento de 2,6 milhões de novos clientes no Brasil. Em maio desse ano, a empresa passou a ofertar venda direta de supermercados, e $20 \%$ dos seus novos compradores usaram o site para diversas categorias de bens, especialmente de alimentos. 
O portal Mobilis registrou um aumento de $149 \%$ de compras com aplicativos de entrega. $\mathrm{O}$ aumento se concentrou em alimentos preparados, mas registrou-se a tendência de aumento do uso do site para diversas aquisições normalmente realizadas (Dau, 2021).

\section{Empresas de delivery}

De 2018 para 2019, mesmo em meio à crise econômica do país, o setor de delivery apresentou uma alta de 23\%. No primeiro trimestre de 2019, a Abrasel (Associação Brasileira de Bares e Restaurantes) divulgou que o crescimento do número de pedidos de aplicativos girou em torno de $\mathrm{R} \$ 1$ bilhão por mês, o que levou o setor a movimentar sozinho cerca de $\mathrm{R} \$ 11$ bilhões no ano (Lima, 2019).

As perspectivas para 2020 eram ainda mais animadoras, mesmo com a retomada lenta da economia. A chegada do coronavírus, no entanto, mudou drasticamente as projeções para o mercado. Era esperada uma alta de 11 a 13\% ao longo do ano (com uma margem maior no interior), sendo que a possibilidade de o mercado dobrar de tamanho não era descartada.

Com o início do isolamento, no entanto, o mercado de delivery passou a ter um crescimento inesperado até então (França, 2020). O crescimento no número de usuários chegou a 155\% entre a segunda quinzena de março e abril, quando o esperado para o período era de $30 \%$. O crescimento do número de pedidos também foi muito além do imaginado, passando de 975\% no mesmo período. Com a perseverança do clima de instabilidade, é difícil prever como o cenário vai se comportar até o final do ano. Mas o esperado é que o crescimento se mantenha em função da população ter se assimilado a essa cultura (França, 2020).

Durante a pandemia, cresceu o número de supermercados, farmácias e até mesmo pet shops que passaram a oferecer o serviço devido às restrições impostas pelo isolamento social. Assim, a pandemia acabou acelerando um processo de adesão ao delivery que já estava acontecendo conforme a Quadro 1.

Quadro 1. Aumento do uso de delivery no período de 15/12/2019 a 31/01/2020. Fonte: França, 2020.

\begin{tabular}{lcc}
\hline & $\begin{array}{c}\text { Antes do Distanciamento Social } \\
(\mathbf{1} / \mathbf{2} / \mathbf{2 0 2 0}-\mathbf{1 5 / 3 / 2 0 2 0})\end{array}$ & $\begin{array}{c}\text { Durante o Distanciamento Social } \\
(\mathbf{1 6 / 3 / 2 0 2 0}-\mathbf{3 0 / 4 / 2 0 2 0})\end{array}$ \\
\hline Pedidos & $1,15 \%$ & $47 \%$ \\
\hline Novos Usuários & $1 \%$ & $155 \%$ \\
\hline Lojas inseridas & $4 \%$ & $29 \%$ \\
\hline
\end{tabular}

Os aplicativos de entrega que já ofereciam serviços para farmácias e supermercados destacaram-se, como a Rappi, que obteve aumento de $92,4 \%$ no valor médio das transações. Já o aplicativo Ifood obteve $22,3 \%$ de aumento. O gasto médio com os principais aplicativos de entrega (Rappi, Ifood e Uber Eats) apresentou aumento de 103\% (Nascimento, 2020). Mas o crescimento do setor não resultou em melhorias para os operadores, que continuam prestando serviços sem vínculo formal de trabalho e sem suporte de EPI ou financeiro na realização de entregas durante a pandemia de COVID19 (Nascimento e Reis, 2020 e Locomotiva, 2020).

\section{Delivery: regime de trabalho e geração de empregos}

Durante a pandemia, prestadores de serviços, mesmo os definidos como essenciais, não usufruíram garantias de trabalho, nem mesmo a provisão de EPI's, se expondo à 
contaminação. No caso de adoecerem, não obtinham dispensa remunerada. Com isso, a exposição aos riscos de saúde não se limitava ao entregador, mas atingia também a população em quarentena.

Para contrapor essa precariedade laboral, o Decreto No 10.329, de 28 de abril de 2020. estabelece obrigações trabalhistas para empresas de serviço de delivery por aplicativo, quais sejam:

a) remuneração a todo entregador que tiver contraído ou contrair, comprovadamente, a Covid-19; e

b) seguro de acidentes pessoais gratuito.

A despeito do projeto de lei, que ainda não foi promulgado, observou-se em pesquisa realizada em São Paulo, Belo Horizonte, Recife e Curitiba que o horário de trabalho anterior à pandemia era mais bem remunerado do que durante após.

No Apêndice 1, estão relatadas informações sobre as condições contratuais colocadas pelas plataformas, adicionadas de observações externadas por artigos jornalísticos e jurisprudências que regraram conflitos entre os operadores e a plataforma.

Os prestadores de serviços por aplicativos acusam, ainda, que o aumento de cadastros de novos entregadores aumentou a oferta e diminuiu os períodos de tarifas dinâmicas e oferta de prêmios, fazendo com que a classe precisasse trabalhar por mais horas para obter os mesmos ganhos. Com relação às medidas protetivas oferecidas pelos aplicativos, $57,7 \%$ dos 270 entrevistados afirmam que não receberam quaisquer materiais para reduzir o risco de contágio e $42,3 \%$ receberam instruções de prevenção ou insumos de proteção. O estudo indica que a maior parte dos entregadores realiza a prevenção com recursos próprios na aquisição de máscaras e álcool em gel (Abílio, et al., 2020).

O relatório de Filgueiras et al. (2020) sobre as condições de trabalho por aplicativo, e que abrangeu todas as regiões do Brasil, apresenta ainda as seguintes informações:

a) Entre os primeiros trimestres de 2015 e 2020, segundo a PNAD contínua, o número de motociclistas ocupados passou de 459 mil para 693 mil;

b) Com a pandemia, em maio de 2020, motoboys e entregadores, ocupações incluídas na PNAD Covid, somaram 917 mil postos;

c) A quase totalidade dos entregadores que responderam à pesquisa é composta por homens (95\%);

d) $32,7 \%$ dos respondentes têm idade entre 18 e 24 anos e $56,5 \%$ têm até 30 anos. A idade mediana apurada é de 28 anos;

e) Os negros, soma dos pretos (19,4\%) ou pardos (39,8\%), são 59,2\%;

f) Assim, o perfil social do entregador por aplicativo que respondeu ao questionário é, na sua maioria, de homens (95\%), jovens de até 30 anos de idade (56,5\%) e negros $(59,2 \%)$;

g) Quanto ao modo de transporte utilizado, os motociclistas são maioria (68,0\%); os ciclistas são 30,1\%; e 93,2\% dos veículos utilizados são de propriedade dos entregadores;

h) Mais de um terço $(37,9 \%)$ dos entregadores indicou trabalhar para uma única empresa; já $72,9 \%$ sinalizaram trabalhar para 1 ou 2 empresas;

i) No total, os entregadores responderam que estão em média nessa ocupação há 10 meses. $71,8 \%$ dos trabalhadores que responderam à pesquisa trabalham há no máximo 1 ano com entregas por aplicativo. Quase um terço $(30,1 \%)$ iniciou na ocupação durante a pandemia da Covid-19; 
j) A grande maioria (89,3\%) trabalha no regime de "nuvem", sem predefinições explícitas de horário ou tempo de trabalho. 7,8\% dos entregadores indicaram que trabalham sob regime mais estável de operadores de logística, com horários prédefinidos;

k) Para 76,7\% dos respondentes a atividade de entrega por aplicativo é sua ocupação principal. 70\% indicaram não possuir outra ocupação;

l) $58,1 \%$ das pessoas que possuem outra ocupação têm nestas suas carteiras de trabalho assinadas. 22,6\% das pessoas, mesmo tendo outra ocupação, têm nas entregas por aplicativo seu trabalho principal;

m) Considerando o total dos entregadores, eles trabalham em média 9 horas e 14 minutos por dia, 5,9 dias/semana, totalizando cerca de 55,2 horas/semana. 70,5\% trabalham 6 ou 7 dias por semana; $68,5 \%$ destes trabalhando 9 ou mais horas/dia;

n) Descriminando por modo de transporte, os motociclistas entregadores por aplicativo participantes da pesquisa trabalham 9 horas e 3 minutos por dia, 5,8 dias por semana, totalizando uma média de 53,8 horas semanais. Já os ciclistas trabalham 9 horas e 32 minutos por dia; 6,1 dias por semana; perfazendo 57,8 horas por semana;

o) Os entregadores que têm neste trabalho a sua única fonte de renda trabalham em média 10,4 horas/dia, 6,2 dias por semana, totalizando uma jornada 64,5 horas semanais, ou seja, 20,5 horas a mais que a jornada semanal recomendada pela legislação trabalhista do país, em trabalho que, já em condições normais, guarda grande risco de acidente;

p) Na comparação entre os rendimentos antes e durante a pandemia, verificou-se que, antes da pandemia, $31,2 \%$ dos rendimentos eram menores que o salário-mínimo (Gráfico 12); e, durante a pandemia, 47,9\% dos rendimentos são menores que o salário-mínimo. Assim, quase a metade dos entregadores ganha menos que 1 salário-mínimo ao final do mês, sem quaisquer outros direitos que o trabalhador com a Carteira assinada tem (férias, FGTS, décimo terceiro, etc.);

q) Quanto ao valor médio declarado geral por entrega, esse é de $\mathrm{R} \$ 6,62$; já o valor mínimo declarado foi de $\mathrm{R} \$ 3,00$ (três reais);

r) Como medida para forçar a fidelidade dos entregadores a despeito das más condições de trabalho e remuneração, a grande maioria dos entrevistados $(71,8 \%)$ acredita que a empresa prioriza os entregadores que permanecem mais tempo logados no aplicativo;

s) Como medida punitiva contra diversas faltas, $38,8 \%$ dos entrevistados afirmam que já foram bloqueados. Só que para 43,7\% não houve transparência acerca das razões do bloqueio. Para $25,2 \%$ o bloqueio foi ocasionado por má conduta do cliente, estabelecimento ou até da própria empresa; para 6,9\%, a recusa ou cancelamento de entregas; para 11,5\%, o mau uso do aplicativo levou ao bloqueio; e ainda 10,3\% relataram outros motivos para o bloqueio. A apenas 2,3\% não informaram;

t) Quanto à segurança do trabalho, um a cada três (33\%) entrevistados já se acidentou neste trabalho. Só que apenas $6,6 \%$ dos entrevistados receberam assistência da empresa; $63,9 \%$ não foram assistidos de nenhuma forma pela empresa; $8,2 \%$ foram bloqueados após o incidente; $8,2 \%$ receberam outros posicionamentos da empresa, e $13,1 \%$ não informaram;

u) Cerca de três a cada quatro entrevistados $(75,7 \%)$ relataram receber pelo menos um material de proteção, como álcool em gel, máscaras e equipamentos de proteção individual;

v) A despeito do regime laboral precário, $87,5 \%$ dos entregadores que declararam não desejar ter a Carteira de Trabalho assinada. Ao explicarem essa recusa, 46,9\% dos entregadores têm receio de perder a flexibilidade; $16,3 \%$ têm medo de ter a remuneração reduzida; uma pequena parte $(10,2 \%)$ não gostaria de ter carteira assinada, pois entende o trabalho das entregas por aplicativo como oportunidade de renda extra. Já 18,4\% relataram ter duplo medo-de perder a flexibilidade e de ter a remuneração reduzida. $8,2 \%$ apresentaram outros motivos. 


\section{Conclusões}

As medidas sanitárias e restrições de aglomeração e de abertura de estabelecimentos que recaíram sobre os diversos setores produtivos e de comércio resultaram em novo comportamento de consumo da população. As novas práticas refletiram na expansão da atuação de supermercados e farmácias no comércio eletrônico e entregas por delivery. $\mathrm{O}$ crescimento do delivery em diversas plataformas foi histórico, conforme demonstrado; e a nova abordagem de atendimento abriu espaço para reorganização do mercado de bens essenciais que se encontrava desestruturado mediante a pandemia.

No presente artigo, foi apresentada a situação particularmente brasileira, à luz de uma crise que afetou a humanidade e retratada e analisada por um grande número de escritos de pesquisa. Dados sobre os impactos sobre diversos setores foram apresentados, para se centrar nas cadeias de suprimento de bens essenciais, nas cadeias de comercialização e, por fim, em um serviço que se beneficiou da situação, que são os serviços de entrega prestados com base de plataformas de delivery.

No caso brasileiro, demonstrou-se que, mesmo diante da tímida reorganização, o mercado não se ajustou completamente, podendo ser observado racionamento de EPIs em hospitais em diversos estados brasileiros. Esse déficit abriu espaço para a hipótese de reestruturação dos setores que compõe a cadeia de bens essenciais.

Em contrapartida, o desenvolvimento acelerado da logística através da expansão do comércio eletrônico revelou ser um processo profundamente reestruturador. No cenário de pandemia, os setores mais resilientes e com capacidade de oferecer respostas mais rápidas às novas demandas foram os que já possuíam fluxo preparado para pedidos online e entregas por meio de delivery, tanto no setor alimentício como de outros bens e serviços essenciais.

Ao mesmo tempo, o sistema de delivery apareceu como um setor gerador de empregos devido ao novo modelo de logística, que integrou grande parte dos aplicativos e das empresas anteriormente terceirizadas.

No entanto, empresas delivery se nutrem de entregadores numa categoria profissional que não possui regulamentação trabalhista, opera em regime de prestador de serviço com CNPJ, num vínculo de informalidade (ONU, 2019). Com dados difíceis de se coletar por falta de transparência das empresas, conseguiu-se, nesse artigo, retratar um mercado de trabalho que sequer é contabilizado como força formal de trabalho, dificultando a elaboração de planos estratégicos para a proteção dos profissionais.

Para além dos efeitos estruturantes sobre as cadeias de suprimento e de logística e de seus impactos nas condições de trabalho dos transportadores, essas transformações estão abrindo um importante veio de pesquisa, assim como de desenvolvimento de plataformas, onde conceitos como torres de controle, logística 5L e economias de rede passam a formar um campo incontornável de produção de análises e publicações.

Tratam-se, pois, de fenômenos disruptivos que irão, em curto prazo, chamar os governos à responsabilidade de enquadrá-los em políticas públicas e medidas regulatórias que, de um lado, impulsionarão seu desenvolvimento e sua integração do sistema econômico renovado, mas, de outro, haverão de controlar os impactos sociais e os perigos de nova concentração de poder econômico. 


\section{Bibliografia}

" Abílio, L. C.; Almeida, P. F.; Armorim, H.; Cardoso, A. C. M.; Fonseca, V. P.; KALIL, R. B. e MACHADO, S. (2020). Condições de trabalho de entregadores via plataforma digital durante a Covid-19. Revista Jurídica Trabalho e Desenvolvimento Humano, Campinas, Brasil. Edição Especial (3), 1-21. ISSN 2595-9689.

»Aquino, J. V. M. A.; Pilate, F. D. Q. e Felix, Y. S. (2020). Uberização do trabalho e os riscos à saúde dos entregadores por aplicativo frente à pandemia de covid-19. Revista Direitos, trabalho e política social, Cuiabá, Brasil. 6(11), 46-69.

" Bosquerolli, A. M.; Fujarra, B. H.; Brandalise, G. A.; Kessey, R.; Colaço, H. M.; Oliveira, H. V.; Santos, L. C. G.; Sarres, L. S.; Alencastro, M. F.; Castroc, M. I.; Podbevsek, T. N. e NIRO, V. R. C. (2020). Brasil e o mundo diante da Covid-19 e da crise econômica. Economia. Brasil e o mundo diante da Covid-19 e da crise econômica. Programa de Educação Tutorial, UFPR, Curitiba, Paraná, Brasil. Recuperado de: https://www.ufpr.br/portalufpr/wp-content/uploads/2020/o7/ Brasil-e-o-mundo-diante-da-Covid-19-e-da-crise-economica.pdf (20/06/2021).

»Chowdhury, P.; Paul, S.; Kaisar, S. e Moktadir, M. (2021). COVID-19 pandemic related supply chain studies: A systematic review. Transportation Research Part E Logistics and Transportation Review. 148(102271). DOI: 10.1016/j.tre.2021.102271.

»Costa, A. S.; Fôro, G. S. S. e Vieira, J. L. (2020). COVID-19 e as cadeias de suprimentos: uma revisão bibliográfica dos principais impactos no Brasil. Revista das Faculdades Integradas Vianna Junior. 11(2) Juiz de Fora. DOI: 10.31994/ rvs.v11i2.687.

"Departamento Intersindical de Estatística e Estudos Socioeconômicos (2020). Análise ICT $\mathrm{n}^{\circ}$ 07. O ICT entre $02^{\circ}$ e $03^{\circ}$ trimestre de 2020. Brasil: Dieese. Recuperado de https://www.dieese.org.br/analiseict/2020/072020.html (10/06/2021).

» Farooq, M.u.; Hussain, A.; Masood, T. e Habib, M.S. (2021). Supply Chain Operations Management in Pandemics: A State-of-the-Art Review Inspired by COVID-19. Sustainability 13(2504). https:// doi.org/10.339o/su13052504

"Fernandes, N. (2020). Economic effects of coronavirus outbreak (COVID-19) on the world economy. IESE Business School Working Paper. Spain. SSRN 3557504.

» Filgueiras, V. A; Siquiera, L. M. L. C.; Almeida, P. A. P.; Avelino, R. S.; Pedreira, S. C. e Silva, V. V. V. B. (2020). Levantamento sobre o Trabalho dos Entregadores por Aplicativos no Brasil. Relatório I de Pesquisa, Universidade Federal da Bahia, Faculdade de Economia, NEC - Núcleo de Estudos Conjunturais, Bahia, Brasil. Recuperado de: http://www.nec.ufba.br/relatorio-de-pesquisa-levantamentosobre-o-trabalho-de-entregadores-por-aplicativo-no-brasil/ (20/06/2021).

»FMI. 2020. World Economic Outlook- October 2020 a Long and Difficult Ascent. Washington, DC: International Monetary Fund. Recuperado de: https://www. imf.org/en/Publications/WEO/Issues/2020/o9/30/world-economic-outlookoctober-2020. ISSN 1564-5215. ISBN 978-1-51355-815-8 (10/06/2021).

"Galhotra, B. e Dewan, A. (2020). Impact of COVID-19 on digital platforms and change in E-commerce shopping trends. Proceedings of the Fourth International Conference on I-SMAC (IoT in Social, Mobile, Analytics and Cloud). Recuperado de: https://ieeexplore.ieee.org/ielx7/9243168/9243301/09243379.pdf(20/06/2021). 
» Gimenez, C. e Sierra, V. (2013). Sustainable Supply Chains: Governance Mechanisms to greening Suppliers. Journal of Business Ethics 116, 189-203. https://doi.org/10.1007/s10551-012-1458-4.

» Gliusti, R.; Manerba, D.; Bruno, G. e Tadei, R. (2019). Synchromodal logistics: An overview of critical success factors, enabling technologies, and open research issues. Transportation Research Part E, 129, 92-110, Italy. https://doi. org/10.1016/j.tre.2019.07.009.

» Góes, F. G. B.; Silva, A. C. S. S.; Santos, A. S.t.; Ávila, F. M. V. P.; Silva, L. J.; Silva, L. F. e Goulart, M. C. L. (2020). Desafios dos profissionais de enfermagem pediátrica frente à pandemia de Covid-19. Revista Latino-Americana de Enfermagem. 28(3367). https://doi.org/10.1590/1518-8345.4550.3367.

»Hofman, W. (2014). Control Tower Architecture for Multi-and Synchromodal Logistics with Real Time Data. sth International Conference - Information Systems, Logistics and Supply Chain. Breda, Netherlands.

"Instituto Brasileiro de Geografia e Estatística. 2020. IBGE Apoiando o Combate à Covid-19. Indicadores de Saúde. Brasil: PNAD COVID19 | IBGE. Recuperado de: https://covid19.ibge.gov.br/pnad-covid/ (10/06/2021).

»Instituto Brasileiro de Geografia e Estatística. 2021. Painel de Indicadores. Brasil: IBGE. Recuperado de https://www.ibge.gov.br/indicadores (30/03/2021).

» Kim, K. (2021). Impacts of COVID-19 on transportation: Summary and synthesis of interdisciplinary research Transportation Research Interdisciplinary Perspectives. 9(100305). https://doi.org/10.1016/j.trip.2021.100305.

" Lassere, F. (2014). Logistics and the Internet: transportation and location issues are crucial in the logistics chain. Journal of Transport Geography, Geography department, Laval University, Québec, Canadá, 12, 73-84.

" Macdonald, Z. (2020). Analysis: Top Selling Products Amid the Coronavirus Crisis - How Demand Is Shifting. Sellics. Recuperado de: https://sellics.com/ blog-coronavirus-covid-amazon-online-shopping/ (20/06/2021).

"Matta, G.C.; REGO, S.: SOUTO, E.P. e SEGATA, J. (2021). Os impactos sociais da Covid-19 no Brasil: populações vulnerabilizadas e respostas à pandemia. Rio de Janeiro: Observatório Covid 19; Editora Fiocruz, 2021, 221 p. Informação para ação na Covid-19 series. ISBN: 978-65-5708-032-o. https://doi. org/10.7476/9786557080320.

»Mehrolia, S.; Alagarsamy, S. e Solaikutty, V. M. (2021). Customers response to online food delivery services during COVID-19 outbreak using binary logistic regression. International Journal of Consumer Studies, 45(3), 396-408. https://doi. org/10.1111/ijcs.12630.

» Meyer, A.; Walter, W. e Seuring, S. (2021). The Impact of the Coronavirus Pandemic on Supply Chains and Their Sustainability: A Text Mining Approach. Frontiers in Sustainability. 2(631182). Doi: 10.3389/frsus.2021.631182.

"Nascimiento, L. L. C. e REIS, C. F. (2020). As condições de trabalho dos entregadores e entregadoras por aplicativos no Brasil durante a pandemia. Revista Princípios. 16o, 112-135. DOI: https://doi.org/10.4322/ principios.2675-6609.2020.160.005.

»Odunayo, A. e Adim, V. (2020). COVID-19 and Supply Chain Disruption: A Conceptual Review. Asian Journal of Economics Business and Accounting. 19, 4047. DOI: 10.9734/AJEBA/2020/v19i230301.

» OECD (2020): E-commerce in the times of COVID-19. Paris, France. OECD. 
Recuperado de: https://www.oecd.org/coronavirus/policy-responses/ecommerce-in-the-time-of-covid-19-3a2b78e8/ (20/06/2021).

»Oliveira, E. M. N.; Carvalho, A. R. B.; Silva, J S.; Neto, A. R. S.; Moura, M. E. B. e Freitas, D. R. J. (2021). Analysis of scientific production on the new coronavirus (COVID-19): a bibliometric analysis. São Paulo Med. J. 139(01) https://doi.org/10.1590/1516-3180.2020.0449.R1.01102020.

»Rajindra, R.; Wekke, I. S.; Sabara, Z.; Pushpalal, D.; Sanadm, N. A. S.; Yani, A. e Umam, R. (2019). Diversity, Resilience, and Tragedy: Three Disasters in Palu of Indonesia. International Journal of Innovation, Creativity and Change, 5(2), 15921607.

» Rustenburg, J. W. (2016). Planning Services: A Control Tower Solution for Managing Spare Parts. Zijm, H., Klumpp, M., Clusen, U., Hompel, M. (Eds.), Logistics and Supply Chain Innovation (239-259). Germany: University of Applied Sciences Essen. DOI: 10.1007/ 978- 3- 319- 22288- 2_14.

"Sabbatini, R. e Fonseca, C. (2021). Covid-19 e o Complexo Econômico-Industrial da Saúde: fragilidades estruturais e possibilidades de enfrentamento da crise sanitária, Cadernos do Desenvolvimento, Rio de Janeiro, Brasil, 16(28), 115-127.

» SEBRAE. 2021. Boletim de Impactos e Tendências da COVID-19 nos pequenos negócios. 24ㄹa ed. Brasil: Sebrae. Recuperado de: https://bibliotecas.sebrae. com.br/chronus/ARQUIVOS_CHRONUS/bds/bds.nsf/4295597c392a7f9b99968 b606fc3e7d7/\$File/30443.pdf (10/06/2021).

» Silber, S. D. (2020). A fragilidade econômica e financeira na pandemia do SarsCovid-19. Estudos. Avançados. 34(100), 107-115. https://doi.org/10.1590/so1034014.2020.34100.008.

»Sinha, D.; Bagodi, V. e Dey, D. (2020). The Supply Chain Disruption Framework Post COVID-19: A System Dynamics Model. Foreign Trade Review, Vol 55(4). https://doi.org/10.1177/0015732520947904.

» Srinivas, S. S. e Marathe, R. R. (2021). Moving towards "mobile warehouse": Lastmile logistics duringCOVID-19and beyond. TransportationResearch Interdisciplinary Perspectives. 10(100339). https://doi.org/10.1016/j.trip.2021.100339.

»Swanson, D. e Santamaria, L. (2021). Pandemic Supply Chain Research: A Structured Literature Review and Bibliometric Network Analysis. Logistics, 5(7). https://doi.org/ 10.3390/logistics5010007.

"Swierczek, A. (2020). The effects of brokered network governance on relational embeddedness in the triadic supply chains: is there a room for the "Coleman rent"?, Supply Chain Management, 25(3), 301-323. https://doi.org/10.1108/ SCM-04-2019-0170.

»Unnikrishnan,A.eFigliozzi, M.(2020).AStudy ofthelmpactofCOVID-19on Home Delivery Purchases and Expenditures. Working Paper. Recuperado de: https:// pdxscholar.library.pdx.edu/cgi/viewcontent.cgi?article $=1576 \&$ context=cengin $\mathrm{fac}(20 / 06 / 2021)$.

"Pham, V.K.; Do Thi, T.H. e Ha Le, T.T.(2020). A study on the COVID-19 awareness affecting the consumer perceived benefits of online shopping in Vietnam, Cogent Business \& Management, 7(1) 1846882, DOI: 10.1080/23311975.2020.1846882.

"Verma S. e Gustafsson, A. (2020). Investigating the emerging COVID-19 research trends in the field of business and management: $A$ bibliometric analysis approach. Journal of Business Research. 118, 253-261. doi:10.1016/j. jbusres.2020.06.057. 


\section{Artigos jornalísticos}

" Dau, G. (20/04/2021) O aumento dos gastos em aplicativos de delivery com a pandemia. Brasil: Jornal Contábil. Recuperado de: https://www.jornalcontabil. com.br/o-aumento-dos-gastos-em-aplicativos-de-delivery-com-a-pandemia/ (21/06/2021).

» Firjan (2020). Boletim de consumo no contexto COVID-19. Brasil: Casa Firjan. Recuperado de: https://casafirjan.com.br/sites/default/files/media/2020/ Boletim-Consumo-contexto-Covid 19_Mai02020_DIPEI.pdf (30/03/2021).

»França, I. (15/09/2020). Desempenho do Delivery no Brasil em 2020. Brasil: Delivery Much. Recuperado de: https://blog.deliverymuch.com.br/delivery-nobrasil/ (10/06/2020).

" Lima, A. P. (11/03/2019). Delivery Movimenta R\$ 11 bilhões por ano enquanto franquias de alimentação diversificam a oferta de produtos. Brasil: SEGS. Recuperado de: https://www.segs.com.br/mais/economia/160266-deliverymovimenta-r-11-bilhoes-por-ano-enquanto-franquias-de-alimentacaodiversificam-a-oferta-de-produtos.

"Locomotiva. 2020. Economia e consumo na era da pandemia. Locomotiva. Recuperado de: https://www.slideshare.net/lLocomotiva/economia-econsumo-na-era-da-pandemia-237791597 (22/11/2020).

» Nascimiento, T. (16/07/2020). Gastos com aplicativos de entrega de comida crescem 103\% no $1^{\text {ํ }}$ semestre. Brasil: Estadão Conteúdo Recuperado de: https://economia.uol.com.br/noticias/estadao-conteudo/2020/07/16/mobilisgastos-com-aplicativos-de-delivery-crescem-103-de-janeiro-a-junho.htm (21/06/2021).

"Sanar Saúde (2020). Pandemias na história: o que há de semelhante e de novo na Covid-19. Brasil: Sanar. Recuperado de: https://www.sanarmed.com/ pandemias-na-historia-comparando-com-a-covid-19 (10/06/2021).

\section{Documentos oficiais}

》Câmara dos Deputados (2020). Decreto nํㅜㅇ‥329, de 28 de abril de 2020. Brasil: Câmara. Recuperado de: https://www2.camara.leg.br/legin/fed/decret/2020/ decreto-10329-28-abril-2020-790135-norma-pe.html (10/06/2021). 


\section{Opêndice 1}

\section{CONDIC̃OES DE TRABALHO NAS PRINCIPAIS PLATAFORMAS DE DELIVERY ATUANTES NO BRASIL}

\begin{tabular}{|c|c|c|c|}
\hline APLICATIVO & $\begin{array}{l}\text { FUNCIONAMENTO E } \\
\text { SERVIÇOS A CLIENTES E } \\
\text { OPERADORES }\end{array}$ & $\begin{array}{l}\text { CONDIÇÕES DE } \\
\text { CONTRATAÇÃO }\end{array}$ & $\begin{array}{l}\text { NÚMERO DE } \\
\text { OPERADORES E } \\
\text { REMUNERAÇÃO }\end{array}$ \\
\hline $\begin{array}{l}\text { LOGGI } \\
\text { Fontes: } \\
\text { LOGGI (2020) Imprensa. Recuperado } \\
\text { de https://imprensa.loggi.com/. } \\
\text { (22/11/2020). } \\
\text { Justiça do Trabalho, TRT 2ª região } \\
\text { - Ação civil pública cível - ACPCiv } \\
\text { 1001058-88.2018.5.02.00o8. Recuperado } \\
\text { de: https://www.jusbrasil.com.br/ } \\
\text { processos/229047117/processo-n- } \\
\text { 1001058-8820185020008-do-Justiça do } \\
\text { Trabalho-2 (21/o6/2021). } \\
\text { Justiça do Trabalho, TRT 2ª região } \\
\text { - Ação civil pública - código: } \\
\text { 18082711424722300ooo11542940o. } \\
\text { Recuperado de: http://www. } \\
\text { sindimotosp.com.br/PDFemgeral/acp- } \\
\text { loggi.pdf (21/o6/2021). }\end{array}$ & $\begin{array}{l}\text { Serviço de Logística e } \\
\text { entrega realizada por } \\
\text { coleta de produto oriundo } \\
\text { de comércio eletrônico e } \\
\text { entrega ao cliente final. } \\
\text { Intermediação e } \\
\text { agenciamento de serviços, } \\
\text { cobranças e informações } \\
\text { cadastrais, agenciamento } \\
\text { de cargas, desenvolvimento } \\
\text { de aplicativos não } \\
\text { customizáveis, serviços de } \\
\text { tecnologia. } \\
\text { Entrega de alimentos } \\
\text { ou produtos com } \\
\text { acompanhamento em } \\
\text { tempo real da entrega por } \\
\text { GPS. } \\
\text { Não há direito de } \\
\text { privacidade sobre os dados } \\
\text { dos contratados } \\
\text { Entregadores sujeitos à } \\
\text { avaliação de terceiros com } \\
\text { publicidade dos resultados. } \\
\text { Preço fixado pelo } \\
\text { aplicativo. }\end{array}$ & $\begin{array}{l}\text { Disponibilidade de carro } \\
\text { ou moto } \\
\text { Entregadores prestadores } \\
\text { de serviço com CNPJ em } \\
\text { regime MEl com CNAE de } \\
\text { serviço de entrega rápida. } \\
\text { O entregador deve possuir } \\
\text { uma série de documentos } \\
\text { comprovando a posse } \\
\text { do veículo, CNH, entre } \\
\text { outros comprovantes que o } \\
\text { habilitam para a entrega. }\end{array}$ & $\begin{array}{l}\text { Número de motoristas o } \\
\text { Brasil: } 5.000 \\
\text { Remuneração: não consta } \\
\text { Condições de trabalho: } \\
\text { não consta. }\end{array}$ \\
\hline
\end{tabular}


IFOOD
Fontes:
IFOOD (2020). Termos. Recuperado de: https://empresas.ifood.com.br/termos/ (22/11/2020).

IFOOD (2020). Nota de esclarecimento. Recuperado de: https://institucional. ifood.com.br/sala-de-imprensa/ comunicado-imprensa-01-07-2020/ (22/11/2020).

Justiça do Trabalho, TRT 2 $2^{\underline{a}}$ região - Ação civil pública cível - 37 - Vara do Trabalho de São Paulo - ACPCiv 1000100-78.2019.5.02.0037. Recuperado de: https://www.jusbrasil.com.br/ processos/233704088/processo-n1000100-7820195020037-do-trt-2 (21/06/2021).
Plataforma que intermedia o contato de restaurantes com entregadores para a realização da entrega de pedidos solicitados pela mesma plataforma ao cliente final.

Gerenciamento dos pedidos realizados pelo aplicativo.

Gestão de Recebimentos e pagamentos de todas as partes

Ferramentas de geolocalização para rastreamento de entregadores ativos e direcionamento de pedidos por proximidade Frete calculado pelas distâncias de coleta, entrega e número de paradas realizadas no percurso

Fundo de amparo a pessoas do grupo de risco ou eventual disponibilização de equipamentos de segurança em decorrência da pandemia de COVID-19

\section{UBER EATS}

Fontes:

UBER (2020). Código de Conduta. Recuperado de: https://www.uber. com/br/pt-br/deliver/basics/tips-forsuccess/uber-community-guidelines/ (22/11/2020).

UBER (2020). Seguro. Recuperado de: https://www.uber.com/br/pt-br/drive/ insurance/ (22/11/2020). Justiça do Trabalho, TRT $2^{\text {a }}$ REGIÃO73Vara do Trabalho de São Paulo ACPCiv 1000436-37.2020.5.02.0073. Recuperado de: https://politica. estadao.com.br/blogs/fausto-macedo/ wp-content/uploads/sites/41/2020/o8/ acpciv-1000436-37202050200731grau_210820202010.pdf(21/06/2021). Bretas, V. Sinal de alerta para o Ifood. Brasil: Istoé Dinheiro. Recuperado de: https://www.istoedinheiro.com.br/sinalde-alerta-para-o-ifood/ (22/11/2020). plataforma. ou invalidez, gastos
Disponibilidade de moto ou bicicleta

Entregadores

colaboradores devem possuir smartphone com acesso à internet e cadastro no aplicativo "Ifood para entregadores"

Os dados exigidos são:

$\mathrm{CNH}$ caso realize entregas pelo modo "motocicleta", dados pessoais e fotografia.
Número de motoristas no Brasil: 170 mil Remuneração:

R\$\$8,oo - Valor médio por rota.

Condições de trabalho: $84 \%$ ficam menos de $6 \mathrm{~h} / \mathrm{dia}$ disponível

61\%receberam em média R\$̣19,00 por hora trabalhada.

\section{Intermédio digital de}

serviços de entrega

conectando cliente final

e restaurante através da

Não há qualquer relação

direta com nenhuma das partes.

Reembolso de itens de proteção

Auxílio à prestadores de serviço diagnosticados

como positivos para COVID-19.

Recomendações de segurança para tráfego aos colaboradores

Estabelecimento de normas para coleta dos alimentos e sua entrega. Seguros: morte, acidente médicos, diárias de R\$180,00 a R\$6oo,oo por incapacidade temporária ou acidente, acionados em casos de acidente de trabalho.

Fundo de R\$̦25milhões para apoio a motoristas durante a pandemia.
Disponibilidade de carro, moto ou bicicleta Entregadores devem disponibilizar fotografia para perfil, veículo utilizado, placa do veículo, modelo do carro, $\mathrm{CNH}$. $\mathrm{CNH}$ com modalidade de "atividade remunerada" Veículos são sujeitos a aprovação para estarem ativos na plataforma.
Número de Motoristas: não consta

Remuneração: Retém taxa de $30 \%$ do valor da entrega (2018)

Condições de trabalho: não consta. 


\begin{tabular}{l}
\hline RAPPI \\
Fontes: \\
RAPPI. (2020). Termos e Condições de \\
uso. Recuperado de: https://legal.rappi. \\
com/brazil/termos-e-condicoes-de-uso- \\
da-plataforma-rappi/ (22/11/2020). \\
RAPPI. (2020). Termos E Condições De \\
Uso De Plataforma Virtual “Entregador \\
Rappi”. Recuperado de: https://legal. \\
rappi.com/brazil/termos-e-condicoes- \\
de-uso-de-plataforma-virtual- \\
entregador-rappi// (22/11/2020). \\
El País - O rápido e inseguro \\
caminho dos 'precários digitais' \\
contra o desemprego. https:// \\
brasil.elpais.com/brasil/ 2018/o7/18/ \\
economia/1531926980_055340.html \\
(22/11/2020).
\end{tabular}

Entrega realizada através de conexão do cliente final e estabelecimento e entregue por motorista que atender à solicitação.

Plataforma com exibição de produtos (cardápios, itens, com respectivas marcas e características) e pagamentos eletrônicos. Não há relação formal entre as partes, sendo o aplicativo, apenas um intermediador das partes. Funcionamento 24 Horas Atende: restaurantes, lojas, supermercados, farmácias, viagens corporativas, entre outros. Cartão Pré-pago para entregador realizar transações solicitadas pelos consumidores.

\section{FOOD}

Fontes:

99FOOD. (2020). Termos de Uso.

Recuperado de: https://food.99app. com/pt-BR/entregador/contract (22/11/2020).

Salomão, K. (18/04/2020) IFood e Rappi: mais entregadores (e mais cobrança por apoio) na pandemia. Brasil: Exame. Recuperado de: https://exame.com/ negocios/coronavirus-leva-maisentregadores-e-gorjetas-aos-apps-dedelivery/ (22/11/2020).
Disponibilidade de moto ou bicicleta
Pessoa física maior de idade

Entregadores cadastrados em regime autônomo prestador de serviços.

"Veículo devidamente adequado para o transporte de produtos conforme legislação"

Despesas arcadas pelo entregador, bem como multas, danos, acidentes, processos administrativos, entre outros. MEI

\author{
Número de motoristas no \\ Brasil: 10.000 \\ Remuneração: não consta \\ Condições de trabalho: \\ não consta.
}

\section{Pedidos de alimentos, bebidas e produtos para restaurantes realizados através de plataforma pelos "compradores" com entrega realizada por prestadores de serviço independentes O entregador é} responsável pelo transporte seguro do produto e deve garantir a sanitização correta durante o percurso até o cliente final

A 99Food expressa que não possui quaisquer vínculos com os entregadores.

O cálculo da entrega é realizado levando em consideração a dificuldade de retirar e entregar o produto, distância e outros fatores

Parcerias com desconto de planos de saúde para os entregadores

Fundo de 10 milhões de dólares para apoio às filiais.
Disponibilidade de carro, moto ou bicicleta

Registro em aplicativo de entrega on-line.

Pessoa Física maior de 18 anos.

Documentação regular Providenciar todos os equipamentos para o

transporte dos produtos Não é liberado uso de outras marcas nos kits de entrega, ou adesivos e enfeites nos veículos.
Número de motoristas: não consta
Remuneração: não consta Condições de trabalho: não consta.

\section{Uly Soares e Melo Pulga / uly.pulga@hotmail.com}

Graduada em Arquitetura e Urbanismo (UNIP). Mestranda em Planejamento Urbano na Universidade de Brasília. 


\section{Joaquim José Guilherme de Aragão / Joaquim.jg.aragao@gmail.com}

Graduado em Engenharia Civil (PUC-Rio). Mestre em Engenharia de Produção (PUCRio). Doutor em Ciências Políticas aplicadas ao Planejamento Territorial (Universidade de Dortmund). Pós-doutorado (University College London, École Nationale de Ponts et Chaussées em Paris e Technische Hochschule Berlin). Professor associado da UnB. Experiência na área de Engenharia de Transportes, Economia dos Transportes. Gerência de Transporte, Regulamentação de Transporte, Financiamento dos Transportes e Geografia dos Transportes.

\section{Yaeko Yamashita / yaekoyamashita@gmail.com}

Engenheira Civil pela Universidade Estadual de Londrina. Mestre pela Universidade de Tottori e PhD pela Universidade de Wales. College of Cardiff. Professora da Universidade de Brasília. Tem experiência nas áreas de Planejamento de Transportes com ênfase em modelagem, sistema de informação geográfica, transporte público urbano e interestadual. 